\title{
Adiciones a un refranero rioplatense del siglo XVIII
}

\author{
José M. Mariluz Urquijo \\ Universidad de Buenos Aires
}

Hace algunos años publicamos una colección de alrededor de trescientos refranes usados en el Río de la Plata durante el siglo XVIII y desarrollamos algunos aspectos relacionados con su utilización ${ }^{1}$. El intento fue anclar cada refrán en su contexto histórico precisando el lugar, el momento y la persona o personas que lo mencionaron. Explicamos allí que empleábamos los términos refranero y refrán en un sentido lato que comprendía tanto a refranes propiamente dichos como a proverbios, adagios, sentencias, brocardos, apotegmas, motes, máximas, proloquios o aforismos, formas afines entre sí y no siempre fáciles de diferenciar pese a los esfuerzos realizados por algunos especialistas.

Posteriores lecturas depararon nuevos hallazgos que ahora publicamos, sabiendo bien que el nuevo aporte sumado al anterior sólo representa una mínima parte del caudal paremiológico circulante en el Setecientos rioplatense. No obstante, creemos que, aunque sea apenas una pequeña muestra de un universo mucho más amplio permite vislumbrar ciertos valores admitidos por los hombres de entonces y conocer algunos de los temas que más les interesaban, proporcionando así una veta aprovechable para el historiador.

Junto con la lengua, el Nuevo Mundo recibió la rica herencia del refranero español del que los americanos hacen un frecuente uso después de adaptarlo a sus propias circunstancias. Como hemos visto en otra oportunidad, prescinden de algunos refranes y aceptan otros en forma original o con intencionadas modificaciones.

${ }^{1}$ José M. Mariluz Urqujo, Refranero rioplatense del siglo xviII, Mendoza, Facultad de Filosofía y Letras de la Universidad Nacional de Cuyo, 1993.

CES.XVIII, núm. 14 (2004), págs. 89-111. 
En el siglo XVIII la utilización del refrán tropieza con una creciente resistencia. Feijoo, que va a ser uno de los autores más leídos del siglo, señala la falibilidad de los adagios, se cuestiona que reflejen la verdad o que sean fruto de la experiencia, y algunos pretenden relegarlos al uso de la gente vulgar e inculta desterrándolos del discurso de los ilustrados. A fines de siglo, en la Península el conde de Floridablanca niega la licencia para imprimir una colección de proverbios árabes alegando secamente que «ya tenemos bastantes», y en América el obispo San Alberto se alarma ante la «perversidad» de algunos refra$n^{2}{ }^{2}$. Pero el refranero estaba demasiado enraizado en la cultura española como para que fuese fácil hacerlo desaparecer de las conversaciones y escritos de la época.

Eusebio de Llano Zapata, culto limeño que conocía bien el virreinato del Perú, incluido el Río de la Plata anterior a su segregación, da testimonio de que a mediados de siglo los refranes eran utilizados a menudo en el teatro «para mover a risa» y de que era muy común que los oradores recurriesen a adagios o proverbios para persuadir con eficacia o para «instruir en útiles advertencias y provechosas máximas a las gentes de cualquier estado y condición». Censura los refranes que incluyen obscenidades o ridiculeces más «propias para entretener cocheros y gañanes que para advertir cortesanos y políticos», pero elogia la prudente utilización de aquellos que «encierran la verdad entre los velos del donaire». Los adagios — dice— «se han de manejar con aquella destreza con que el sabio artífice engasta el diamante en el anillo y entreteje el oro con la púrpura, proporcionándolos con tal arte que parezca que la piedra vino unida al metal y se tejieron a un tiempo la grana con $\mathrm{el}$ oro $^{3}{ }^{»}$.

La gran variedad de refranes y las distintas finalidades a las que apuntan ofrecen múltiples opciones para que cada uno pueda seleccionar lo que le conviene, y la distinción insinuada por Llano Zapata entre refranes chocarreros y proverbios moralizantes o educativos da pie para que sean utilizados por personas de muy distinta extracción social y diferente nivel de instrucción. Magistrados como Antonio Porlier anotan los refranes que les parecen más adecuados para reglar su vida; obispos como Manuel Antonio de la Torre hacen un uso tan abundante e indiscreto que erizan la sensibilidad ilustrada de quienes desprecian lo que puede oler a populacho; dramaturgos como Cristóbal de Aguilar o marinos como Francisco de Aguirre echan mano frecuentemente de algún refrán que, al reflejar una verdad admitida por todos, les ahorran tener que entrar en

\footnotetext{
2 Ídem, pág. 16.

${ }^{3}$ José Eusebio de Llano Zapata, Paremiógrafo hispano latino que ofrece y dedica a la estudiosa juventud peruana, Lima, 1752.
} 
razonamientos y argumentaciones para justificar lo que sostienen. Con un refrán oportunamente aplicado se termina una discusión con el peso de una autoridad que es respaldada por el consenso social, o se comenta un episodio aislado inscribiéndolo en un marco más general, abarcador de otros casos similares. Así, Domingo Faustino Sarmiento da cuenta en sus Recuerdos de Provincia de que su madre evocaba a don Luciano Mallea «sentencioso en sus palabras [...], que tenía un adagio o un verso para cada ocurrencia de la vida ${ }^{4}$.

De las voces del ayer que hoy convocamos aquí, el padre Dobrizhoffer es el más aficionado a apoyarse en el refranero. Natural de Friedberg, a veces cita algún refrán aprendido antes de integrarse al mundo cultural hispánico, pero otras reproduce el refrán en español tal como lo ha oído durante su estada en el Río de la Plata o, como escribe durante su destierro posterior al extrañamiento de la Compañía de Jesús, lo introduce con un «ellos solían decir» revelador de que está recogiendo frases que oyó en el Nuevo Mundo.

En ocasiones quien emplea un refrán acuñado en la Península no se limita a enunciarlo, sino que refuerza su vigencia afirmando que es especialmente válido en tierras de América o dentro de una determinada etnia radicada en suelo rioplatense o, por el contrario, reflexiona que no es aplicable en América. Otras veces vigoriza el refrán con el respaldo que le da algún pasaje coincidente de las Sagradas Escrituras o con la mención de que es confirmado por la experiencia o recuerda alguna ocasión en la cual el adagio reflejó exactamente lo ocurrido.

Aunque en la mayoría de los casos se consigna el refrán íntegramente, en ocasiones se prefiere sugerirlo mencionando sólo el principio o desarticularlo, en la seguridad de que el lector sabrá cómo terminarlo o recomponerlo.

Si algunos oídos delicados repugnasen la tosquedad de ciertas expresiones recogidas aquí, contestaremos con la autorizada voz del maestro de latinidad y elocuencia de la villa de Valdepeñas, licenciado Gerónimo Martín Caro y Cejudo, quien a fines del siglo XVIII pensaba que no correspondía limar expresiones malsonantes, «pues no se debe mudar la forma antigua de los refranes ni los términos vulgares con que se dicen», sino reproducirlos fielmente ${ }^{5}$.

Se ha dicho con verdad que uno de los caracteres más salientes del refranero hispano era su «universal misoginia ${ }^{6}$, por lo que nosotros observamos

\footnotetext{
${ }^{4}$ Domingo Faustino Sarmiento, Recuerdos de Provincia, prólogo de Alberto Palcos, Buenos Aires, 1953, pág. 33.

${ }^{5}$ Gerónimo Martín Caro y Cejudo, Refranes y modos de hablar castellanos con los latinos que les corresponden y la glosa y explicación de los que tienen necesidad de ella, Madrid, 1792, pág. x.

${ }^{6}$ Mauro Fernández, Diccionario de refranes, Madrid, 1994, pág. 9. Después de analizar el Vocabulario de Refranes de Gonzalo Correas, una autora concluye que «más de trescientos proverbios evocan insuficiencias,
} 
con cierta sorpresa que entre los refranes que habíamos coleccionado en 1993 no se contaba ninguno de sabor antifeminista sino que, por el contrario, registrábamos casos de una valoración positiva de la esposa o casos de haberse modificado significativamente el modelo español para desactivar su original carga antifeminista. Y nos preguntábamos si se trataba de una simple casualidad o era señal reveladora de un distinto contexto social. El aporte que ahora publicamos no introduce variantes en aquella constante, de modo que el interrogante sigue en pie.

Como hicimos anteriormente, no omitimos recoger más de una vez un mismo refrán si es otro pasaje donde aparece por entender que su utilización aislada o reiterada es un índice de su menor o mayor aceptación. Entonces como ahora, extendemos la centuria hasta 1810, fecha de iniciación del movimiento revolucionario contra España. Para que pueda apreciarse la fidelidad o adecuación de la versión rioplatense, procuramos ofrecer también el mismo refrán tal como figura en otros refraneros.

Estamos muy lejos de pensar que los refranes publicados aquí completan la colección que dimos a conocer en 1993, pero creemos que junto a ella permiten entrever algo de las ideas y creencias del hombre rioplatense del siglo XVIII.

Chaco, mediados del siglo XVIII

"Así como las águilas no generan palomas; sin embargo a menudo es cierto esto otro: los crímenes son hijos de héroes».

Martín Dobrizhoffer, Historia de los abipones (adv. de Ernesto J. A. Maeder), t. II, Resistencia, 1968, pág. 112.

—Del águila no nace la paloma (SP).

Chaco, mediados del siglo XVIII

«en el refrán español dice: alazán tostado antes muerto que cansado».

Martín Dobrizhoffer, Historia de los abipones, t. I, Resistencia, 1967, pág. 106.

—Alazán tostado antes muerto que cansado (C 24).

Reducción de San Javier, 1749-1767

Recuerda «la divina sabiduría que al buey que trilla no se le debe atar la boca».

\footnotetext{
defectos, vicios particulares de las mujeres mientras que sólo seis presentan cualidades de las mismas: cfr. Marie Catherine Barbazza, «La mujer en el Vocabulario de Refranes de Correas: ¿un discurso de exclusión?», en Revista de Estudios Extremeños, t. XLVII, núm. 2 (1990), pág. 430.
} 
Florián Paucke, Hacia allá y para acá (adv. de R. A. Altieri), t. II, Tucumán, 1943, pág. 191.

- No pondrás bozal al buey que trilla tus mieses en la era (Deuteronomio, $\mathrm{XX}, 4)$.

Chaco, mediados del siglo XVIII

«de donde el proverbio español: al moro muerto gran lanzada».

Martín Dobrizhoffer, Historia de los abipones, t. II, pág. 139.

-A moro muerto gran lanzada (HN).

Buenos Aires, 16-IX-1808

«Esto es la verdad que digo a $\mathrm{Vm}$. reservadamente y al que le venga el sayo que se lo ponga».

Jaime Alsina y Verjés a Luis de la Cruz.

Copiador de cartas de Jaime Alsina a Verjés, t. I (1807-1809), f. 282 v., AGN, Fondo y colección de José Juan Biedma, sala VII, núm. 1061.

-A quien le venga el sayo, que se lo embone ¿RM I?

Buenos Aires, 1808

«al que le vaya el sayo que se lo ponga».

Jaime Alsina a Carlos Camusso.

Gabriela dalla CoRTe, Vida i mort d'una aventura al Riu de la Plata. Jaime Alsina y Verjés 1770-1836, Barcelona, 2000, pág. 121.

-A quien le venga el sayo, que se lo embone (RM I).

Córdoba, siglo XVIII

«amicus Plato sed magis amica veritas».

Pedro Lozano, Historia de la Compañía de Jesús en la Provincia del Paraguay, t. I, Madrid, 1754, pág. 136.

-Amicus Plato sed magis amica veritas (Horacio).

Montevideo, fines del siglo XVIII

«a muertos y a idos no hay amigos».

Cayetana Ross y Pozo a Facundo de Prieto y Pulido.

Martín de ElizALDE, «Cartas de Montevideo (1796-1798)», en Idea viva, núm.

7 (agosto de 2000), Buenos Aires, pág. 34.

-A muertos y a idos pocos amigos (C). 
Montevideo, fines del siglo XVIII

«a muertos y a idos no hay amigos».

Cayetana Ross y Pozo, viuda del capitán Juan González Bordallo a Facundo de Prieto y Pulido.

Martín de ElizALDE, «Cartas de Montevideo», en Estudios de filología y retórica en homenaje a Luisa López Grigera, Bilbao, 2000, pág. 223.

-A muertos y a idos pocos amigos (C).

Reducción de San Javier, 1749-1767

«Cuando íbamos a partir se me acercó don Narciso Echagüe y me apretó a la mano tres piezas de moneda de oro portuguesa y dijo a la vez antes mártir que confesor con lo que quiso decir que si en el camino éramos revisados yo me hiciera martirizar antes que confesar de quién había recibido este dinero».

Florián PAucke, Hacia allá y para acá, t. III, 1. a parte, pág. 93.

-Antes mártir que confesor (D A).

Montevideo, 9-IX-1787

«en estos negocios tan delicados como unirse uno a otro se ha de proceder con mucho tiento y tener en la memoria aquel refrán antes que te cases mira lo que haces porque parece juego de niños decir hoy que sí y mañana que no».

Manuel Joaquín de Toca a su madre.

AGI, Audiencia de Buenos Aires, 568. Transcripta en Adolfo Elizaincín, Marisa Malcuori y Virginia Bertoloti, El español en la Banda Oriental del siglo XVIII, Montevideo, 1997, pág. 75.

—Antes que te cases mira lo que haces (F E).

Buenos Aires, 1772

«Un proverbio de las sabias Partidas dice que el apelante debe ser favorecido en sus recursos como aquel navegante que viéndose en los peligros del mar busca puerto para libertarse del naufragio».

AGN, IX-41-5-2. Citado por María Rosa Pugliese, «El uso de la voz justicia en los tribunales del Río de la Plata durante el período virreinal», en Tercer Congreso Argentino de Americanistas, t. I, Buenos Aires, 2000.

-Part. III, tít. XXIII: De las alzadas que fazen las partes.

«Esto es todo lo que de ordinario se dice buena cara tienes, buenos hechos harás, que este adagio español parece que cifró todo cuanto los antiguos filósofos dijeron en los suyos». 
Bartolomé Arzáns de Orsúa y Vela, Historia de la Villa Imperial de Potosí, ed. de Lewis Hanke y Gunnar Mendoza, t. II, Providence, Rhode Island, 1965.

- Buena cara tienes, buenos hechos harás $(\mathrm{C})$.

Chaco, mediados del siglo XVIII

Los caballos engordan «tanto que sobre su lomo se podrían contar los pesos como sobre una mesa, refrán que los españoles suelen usar con referencia a los caballos gordos».

Martín Dobrizhoffer, Historia de los abipones, t. I, pág. 331.

Buenos Aires, 1808

«Que cada uno gobierne su casa y Dios la de todos».

Jaime Alsina a Julián de Urmeneta.

Gabriela dalla Corte, Vida i mort d'una aventura al Riu de la Plata, pág. 136.

— Cada uno en su casa y Dios en la de todos (C).

Río de la Plata, fines del siglo XVIII

«La entidad de estos robos se consideró menos que el de la misma provincia y no faltan quienes digan hubo también capa con que cubrirse».

Juan Francisco Aguirre, Discurso histórico sobre el Paraguay, estudio preliminar y restitución del texto por Ernesto J. A. Maeder, Buenos Aires, 2003, pág. 494.

- La buena capa encubre al ladrón (MK).

Chaco, mediados del siglo XVIII

«Según el proverbio de los europeos carece de todo quien carece de dinero». Martín Dobrizhoffer, Historia de los abipones, t. I, pág. 106.

—¿Quién vio mal tan lastimero como carecer de dinero? (Sbarbi X).

Chaco, mediados del siglo XVIII

«El ciego soñaba que veía y soñaba lo que quería».

Martín Dobrizhoffer, Historia de los abipones, t. I, pág. 315.

—Soñaba el ciego que veía y soñaba lo que quería (D A).

Buenos Aires, 4-II-1799

«aquel adagio que dice que un clavo saca otro clavo».

Francisco de Serra Canals, El perito incógnito y el curioso aprovechado, estudio preliminar, transcripción y glosario por Edberto Oscar Acevedo, Frankfurt-Madrid, 1999, pág. 89.

-Un clavo saca otro clavo (RM I). 
Chaco, mediados del siglo XVIII

«Como el amor enciende el amor y el fuego al fuego, así la libertad prepara amigos. Este adagio tan conocido en Europa lo pusimos en práctica con los abipones dando resultados verdaderamente positivos».

Martín Dobrizhoffer, Historia de los abipones, t. II, pág. 110.

Córdoba, 23-VIII-1768

«Confesión de parte, relevación de prueba, dice el adagio de las curias».

El obispo del Tucumán Manuel Abad Illana al Rey.

P. A. Larrouy, Documentos del Archivo de Indias para la historia del Tucumán, t. II, Tolosa, 1927, pág. 301.

—A confesión de parte relevación de prueba (RM I).

Chaco, mediados del siglo XVIII

«estos confirman con su ejemplo que cuanto más fino es el vino, mayor es la calidad del vinagre y que la corrupción de los mejores es la peor».

Martín Dobrizhoffer, Historia de los abipones, t. II, pág. 140.

- Corruptio optimi, pessima.

—De la corrupción de lo mejor sale lo peor (MK).

Paraguay, 30-IX-1761

«siendo cierto y máxima del derecho que la cosa siempre perece para su dueño».

El obispo Manuel de la Torre al Rey.

Historia Paraguaya, vol. XXXI (II), Asunción, Academia Paraguaya de la Historia, 1993, pág. 242.

-Res perit domino.

Córdoba, 7-XII-1770

«las cosas que solas no aprovechan, juntas todas ayudan», como dice Francisco Carrasco en De recusationes.

Juan Manuel Fernández Campero a la Junta Provincial de Temporalidades.

Edberto Óscar AcEvedo, La rebelión de 1767 en el Tucumán, Mendoza, 1969, pág. 172.

Italia, 1770

«Cebados los mamelucos con tanto botín, como la codicia aumenta las ganas de tener más, según el otro: crescit amor nummi quantum ipsa pecunia crescit, prosiguieron detrás de los trasmigrados hacia el río Uruguay». 
José Cardiel, Breve relación de las misiones del Paraguay, en Pablo HerNÁNDEZ, Organización social de las doctrinas guaranies de la Compañía de Jesús, t. II, Barcelona, 1913, pág. 520.

—Crescit amor nummi quantum pecunia crevit (Juvenal, sátira XIV, verso 139). Posiblemente Cardiel ha manejado alguna de las varias ediciones de Juan de Lama, Florilegium latinum sive hortus proverbiorum, que ofrece la misma versión de Juvenal que él utiliza.

Córdoba, siglo XVIII

«Si en todos es verdad que dádivas quebrantan peñas en el genio interesable de estos bárbaros son todavía armas de mayor poder».

Pedro Lozano, Historia de la Compañía de Jesús en la Provincia del Paraguay, t. II, pág. 310.

—Dádivas quebrantan peñas y justicias por más señas (RM I).

Córdoba, 23-VIII-1768

«Idos los Padres se fue con ellos la Universidad que a ellos estaba agregada. Deficiente principali corruit accesorium».

El obispo del Tucumán Manuel Abad Illana al Rey.

P. A. Larrouy, Documentos del Archivo de Indias para la historia del Tucumán, t. II, pág. 311.

—Lo accesorio se extingue con lo principal (JGI).

Asunción, fines del siglo XVIII

Algunos políticos proponen medidas que favorecerían al Paraguay pero que perjudicarían al Tucumán, lo que equivale a «desnudar a un santo para vestir a otro».

Julio Ramón de CÉsar, Noticias del Paraguay, estudio preliminar de Beatriz Rodríguez Alcalá de González Oddone, Asunción, 2002, pág. 77.

-Desvestir a un santo para vestir a otro cosa es de bobos (RM I).

\section{Córdoba, siglo XVIII}

Gonzalo de Abreu «dióse en acompañar con personas de pocas obligaciones y estas eran las que con él más valían y las que él más atendía y como la sentencia dime con quien andas, diréte quien eres es tan verdadera como calificada por la experiencia y aun aprobada del Santo Rey profeta en el salmo 17, se le pegaron mucho sus ruines costumbres».

Pedro Lozano, Historia de la conquista del Paraguay, Río de la Plata y Tucumán, ilustrada con noticias del autor y con notas y suplementos por Andrés Lamas, t. IV, Buenos Aires, 1874, ppág. 311-312. 
—Dime con quien andas y te diré quien eres (Sbarbi IV).

\section{Montevideo, 1787}

$\mathrm{Al}$ ocuparse de la moda femenina afirma que «no hay materia en que se pueda hablar con menos seguridad que ésta y el que oye es menester que ande siempre por su laberinto con el hilo de Ariadna, quiero decir, con la regla de distingue tempora y sería muy del caso que se proveyese de alguna otra, como la de distingue persona, loca, circunstancias, etc.».

Juan Manuel Pérez Castellano, «Carta escrita para la Italia», en Fernando Mañé Garzón, Vida y obra de José Manuel Pérez Castellano (1742-1815), t. III (apéndice documental), Montevideo, 2003, pág. 36.

—Distingue tempora et concordabis jura.

Córdoba, 19-XII-1788

«la regla distingue tempora et concordabis jura».

Defensa de un curandero por José Cordero Galindo.

Marcella Aspell de YANZI FerReIRA, «De ángeles, sapos y totoras quemadas», separata de la Revista de la Facultad (Córdoba, Argentina), núm. 4, vol. 2 (1997).

—Distingue tempora et concordabis jura.

Córdoba, siglo XVIII

«según el adagio vulgar donde hay llaga escuece la trementina».

Pedro Lozano, Historia de la Compañía de Jesús en la provincia del Paraguay, t. I, pág. 471.

Montevideo, hacia 1789

$\mathrm{Al}$ referirse al matrimonio entre los indígenas comenta que «como los duelos con pan son menos, el dolor que naturalmente sienten los padres de desprenderse y separarse de su hija, se mitiga con el lenitivo de los regalos que les hacen los novios».

José Manuel Pérez Castellano, «Sobre algunas palabras de la lengua auca o araucana», en Fernando Mañé Garzón, Vida y obra de José Manuel Pérez Castellano (1742-1815), t. III (apéndice documental), Montevideo, 2003, pág. 79.

-Todos los duelos con pan son menos (F E).

Esmoraca, 16-XI-1800

«Viva v. seguro que yo sigo aquel aforismo dum fueris Romae, romano vivito more».

José Antonio Carballo a Vicente Anastasio Echevarría. 
Archivo Marc, Rosario.

— Si Roma fueris romano vivito more (RM I).

Chaco, mediados del siglo XVIII

«Si como dice el apóstol Pablo en otros pueblos la fe entra por los oídos entre los bárbaros paracuarios puede, acaso, como lo expresa el adagio, ser ingerida por la boca».

Martín Dobrizhoffer, Historia de los abipones, t. III, pág. 353.

-San Pablo, Ad romanos, X, 17.

Chaco, mediados del siglo XVIII

«Pues feliz no es el que posee mucho sino quien necesita poco».

Martín Dobrizhoffer, Historia de los abipones, t. I, pág. 106.

-No es rico el que mucho tiene sino el que nada apetece (RM).

Chaco, mediados del siglo XVIII

«Aunque en Europa el hábito no hace al monje, en América, sin embargo, el vestido más noble hace al noble según el juicio de los abipones».

Martín Dobrizhoffer, Historia de los abipones, t. II, pág. 106.

—El hábito no hace al monje (MK).

Córdoba, siglo XVIII

«que al fin el hábito no hace al monje sino las costumbres santas».

Pedro Lozano, Historia de la Compañía de Jesús en la Provincia del Paraguay, t. II, pág. 701.

—El hábito no hace al monje (MK).

Asunción, fines del siglo XVIII

Elegí como confesor a un sacerdote que parecía un bandolero pero que resultó excelente. «Gracias a Dios Todopoderoso que se cumplió aquí el adagio o verdadera sentencia que el hábito no hace al monje».

Julio Ramón de Cesar, Noticias del Paraguay, pág. 294.

—El hábito no hace al monje (MK).

Buenos Aires, 1808

«el que no habla ni Dios lo oye».

Jaime Alsina a Carlos Camusso.

Gabriela dalla CoRTe, Vida i mort d'una aventura al riu de la Plata, pág. 23.

-Boca que no habla, Dios no la oye (RM I). 
Buenos Aires, 22-II-1804

«Hijo tardano, huérfano temprano» dice un refrán español: triste reflexión para los que se hallan en el caso de tener esa desgracia».

Benjamín Franklin a Juan Alleyne.

Semanario de Agricultura, Industria y Comercio, t. II, Buenos Aires, 1804, pág. 195.

- Hijo tardano, huérfano temprano (C).

Buenos Aires, 1797

«El gran Genovesi dice que la máxima de Cicerón, honos alit artes, es sacada de la naturaleza y de la historia humana y, en verdad señores, que la experiencia constante de todos los tiempos y de todos los siglos así nos lo enseña».

Manuel Belgrano, Memoria presentada al Consulado de Buenos Aires.

Córdoba, 6-VIII-1787

«Así se aumenta la honra pero tengo el gusto que honor filii est gloria parentis así como es el del discípulo para su maestro».

Domingo Belgrano a su padre.

Instituto Nacional Belgraniano, Documentos para la historia del general don Manuel Belgrano, t. III, segunda parte, Buenos Aires, s.d., pág. 129.

Reducción de San Javier, 1749-1767

«Honor fugientem sequitur. Sequentem fugit».

Florián PAucke, Hacia allá y para acá, t. III, 1. parte, pág. 108.

-Honor sequentem fugit \& contemnentem quaeritat (Gerónimo Martín Caro y Cejudo, Refranero y modos de hablar castellanos con los latinos que les corresponden y la glosa de los que tienen necesidad de ella, Madrid, 1792, pág. 169).

Córdoba, 6-VIII-1787

«lo que a mí me parece es que huyendo de las llamas caemos en las brasas».

Domingo Belgrano a su padre.

Instituto Nacional Belgraniano, Documentos para la historia del general don Manuel Belgrano, t. III, segunda parte, pág. 129.

-Huí de la llama y caí en la brasa (C).

Montevideo, 1810

«En todos tiempos aconseja el adagio español que se haga del ladrón, fiel ¿y será prudencia en estos tan turbados, en que nuestro gobierno está vacilante 
como nuestro poder, empeñarse por miras particulares de interés y ambición el hacer de un fiel un desleal?»

José Manuel Pérez Castellano a Miguel de Lardizábal y Uribe.

Fernando Mañé Garzón, Vida y obra de José Manuel Pérez Castellano (17421815), t. III (apéndice documental), Montevideo, 2003, pág. 171.

- ¿Quieres hacer del ladrón fiel? Fíate dél (HN).

Chaco, mediados del siglo XVIII

«Como reza el adagio español fueron a buscar lana pero volvieron esquilados». Martín Dobrizhoffer, Historia de los abipones, t. II, pág. 377.

-Fuese por lana y volvió trasquilado (C).

Montevideo, fines del siglo XVIII

«se puede decir con verdad que recurriendo el Gobernador a la Corte por lana salió completamente trasquilado».

- Ir por lana y volver trasquilado (C).

Rávena, 1770

«Lo que se acaba de escribir es suficiente para dar a conocer, como el león por su uña, el natural de la nación eyiguayagui».

José Sánchez Labrador, El Paraguay católico, t. I, Buenos Aires, pág. 287.

-Ex ungue leonem.

Montevideo, 1810

«Yo supongo que de todo habrá dado cuenta don Joaquín de Soria pero como lo que abunda no daña, le incluyo a V.E. copia del oficio suyo».

José Manuel Pérez Castellano a Miguel de Lardizábal y Uribe.

Fernando Mañé Garzón, Vida y obra de José Manuel Pérez Castellano, t.

III, pág. 187.

—Lo que abunda no daña (RM I).

Buenos Aires, 1808

«o que no quieras para ti no debes querer para tu hermano».

Jaime Alsina a Pedro Martínez Sanz.

Gabriela dalla Corte, Vida i mort d’una aventura al Riu de la Plata, pág. 115.

—Lo que no quieras para ti no lo quieras para otro (Sbarbi II). 
Buenos Aires, 1808

«El adagio dice que el mal de muchos es consuelo de bobos».

Jaime Alsina a Julián de Urmeneta.

Gabriela dalla Corte, Vida i mort d’una aventura al Riu de la Plata, pág. 103.

- Mal de muchos, consuelo de tontos (RM I).

Buenos Aires, 8-VI-1781

«Marea llena, marea vacía».

Bartolomé Ferrer a su esposa.

Isabelo Macías y Francisco Morales Padrón, Cartas de América, Sevilla, 1991, pág. 216.

-A gran llena, gran vacía (MK).

Chaco, mediados del siglo XVIII

«como dice el proverbio más vale ser cabeza de ratón que cola de león».

Martín Dobrizhoffer, Historia de los abipones, t. II, pág. 107.

—Más vale ser cabeza de ratón que cola de león $(\mathrm{C})$.

Córdoba, 23-VIII-1768

«si en todo litigio melior est conditio possidentis, no pierda Córdoba en esta demanda».

P. A. Larrouy, Documentos del Archivo de Indias para la historia del Tucumán, t. II, pág. 314.

—Melior habetur possessoris causa (Paulus, lib. 154).

Córdoba, siglo XVIII

«Como según el adagio castellano no hay mentira que no sea hija de algo...».

Pedro Lozano, Historia de las revoluciones del Paraguay, t. I, pág. 276.

—La mentira siempre es hijadalgo (RM I).

Chaco, mediados del siglo XVIII

«en verdad, para usar un adagio español mucho era el ruido pero pocas las nueces».

Martín Dobrizhoffer, Historia de los abipones, t. III, pág. 268.

-Más es el ruido que las nueces.

Cuzco-Buenos Aires, 1787

«Cuatro mudanzas de casa se compara a un incendio, dice un erudito político moderno». 
Benito de la Mata Linares a Marqués de Sonora. Real Academia de la Historia, Colección Mata Linares. Agradecemos a la doctora María Rosa Pugliese la comunicación de este texto.

—Tres mudanzas equivalen a un incendio (RM I).

\section{Chaco, mediados del siglo XVIII}

«un mular sirve a su amo, como dice el proverbio español, durante setenta años para poder matarlo, a veces, finalmente. La verdad de este proverbio se confirma por una cantidad de sucesos trágicos que yo mismo he visto».

Martín Dobrizhoffer, Historia de los abipones, t. I, pág. 347.

- La mula mansa a su amo mata (MK).

\section{Paraguay, 30-IX-1761}

Los comerciantes que introducen los artículos que llegan de Buenos Aires pretenden obtener exorbitantes ganancias «paliando esta injusticia con que las cosas van al fiado y obligando a los pobres paraguayos la necesidad (que carece de ley) a tomarlas para cubrir su desnudez».

El obispo Manuel Antonio de la Torre al rey.

Historia Paraguaya, vol. XXXII (II), Asunción, Academia Paraguaya de la Historia, 1993, pág. 238.

-A necesidad no hay ley (MK).

\section{Montevideo, 1808}

«Si se tiene a mal que Montevideo haya sido la primera ciudad de América que manifestase el noble y enérgico sentimiento de igualarse con las ciudades de la Madre Patria... la obligaron a eso circunstancias que son notorias y no es un delito ceder a la necesidad».

José Manuel Pérez Castellano al obispo Benito Lué.

Fernando Mañé Garzón, Vida y obra de José Manuel Pérez Castellano, t. III, pág. 195.

—A necesidad no hay ley (C).

Plata, 25-IV-1810

«No hagas cohecho ni pierdas derecho».

Condesa de Argelejo a José Fernando Abascal y Sousa.

Daisy Rípodas Ardanaz, «La administración de justicia en el último siglo colonial. Una imagen a través de la literatura dieciochesca de América Meridional», en Revista de Historia del Derecho, núm. 20, Buenos Aires, 1992, pág. 379.

-Ni perder derechos ni llevar cohechos (MK). 
Asunción, fines del siglo XVIII

«En la festividad de Nuestra Señora del Carmen quise confesarme para cumplir el refrán no hay p[uta] ni ladrón que no tenga su devoción».

Julio Ramón de CÉSAR, Noticias del Paraguay, Ms. en la Real Academia de la Historia, col. Mata Linares, t. LX. En la edición paraguaya se lee, pág. 294, «no hay padre ni ladrón que no tenga su devoción».

—No hay puta ni ladrón que no tenga su devoción (MK).

Chaco, mediados del siglo XVIII

«no todo lo que reluce es oro o diamante».

Martín Dobrizhoffer, Historia de los abipones, t. I, pág. 305.

-No es oro todo lo que reluce (RM I).

Córdoba, siglo XVIII

«La experiencia enseña que no es oro todo lo que reluce».

Pedro Lozano, Historia de la Compañía de Jesús en la Provincia del Paraguay, t. II, pág. 149.

-No es oro todo lo que reluce (RM I).

Río de la Plata, fines del siglo XVIII

«Nunca se conoce mejor el bien que cuando perdido".

Juan Francisco de Aguirre, Discurso histórico sobre el Paraguay, estudio preliminar y restitución del texto por Ernesto J. A. Maeder, Buenos Aires, 2003, pág. 153.

—El bien nunca es conocido hasta perdido ( $\mathrm{F} \mathrm{E}$ ).

Córdoba, mediados del siglo XVIII

«Decíase que habían oído las campanas de los Césares para las funciones eclesiásticas pero que no se pudo atinar con la ciudad donde sonaban. Eso es precisamente oír campanas y no saber dónde».

José Guevara, «Historia del Paraguay, Río de la Plata y Tucumán», en Anales de la Biblioteca, t. V, Buenos Aires, pág. 298.

-Oír campanas y no saber dónde (Delfín Carbonell Basset, Diccionario panhispánico de refranes, Barcelona, 2002).

Córdoba, 19-XII-1788

«Nuestras leyes prohíben el que se permita curar al que no sea médico aprobado pero también se debe tener presente que la necesidad carece de ley y aquella prohibición tiene su propio lugar en los países que cuando no sobran al menos no faltan facultativos legítimamente aprobados». 
Defensa de un curandero por José Cordero Galindo.

Marcela Aspell de YAnzi FERREIRA, «De ángeles, sapos y totoras quemadas», pág. 77.

-A necesidad no hay ley (C).

Chaco, mediados del siglo XVIII

«Ellos solían decir ni mulas ni mulatos es decir que no había que fiarse ni de mulares ni de mulatos».

Martín Dobrizhoffer, Historia de los abipones, t. I, pág. 349.

-Con mulos y mulatos poco trato (RM I).

Córdoba, siglo XVIII

«verificándose a la letra el común proverbio que no es conocido el bien hasta que es perdido».

Pedro Lozano, Historia de la Compañía de Jesús en la Provincia del Paraguay, t. II, pág. 608.

—El bien nunca es conocido hasta que es perdido (F E).

Plata, 15-VII-1790

«en fin ya avisarán y todo tendrá su debido cumplimiento pues no se ganó Zamora».

Joaquín del Pino a José Pérez de Brito y a su hija María Josefa.

Un epistolario virreinal. Cartas familiares de don Joaquín del Pino y Rozas VIII virrey del Río de la Plata, edición de José María Martínez Vivot, Madrid, 2001, pág. 30.

—No se ganó Zamora en una hora (C).

Chaco, mediados del siglo XVIII

«Sobre los leones paracuarios recae el viejo refrán de los españoles no es tan bravo el león como lo pintan».

Martín Dobrizhoffer, Historia de los abipones, t. I, pág. 366.

—No es tan bravo el león como lo pintan (Sbarbi I).

Timbó, 12-X-1764

«en lugar de pensar que yo pinto al león más bravo de lo que es se admirarían de mi valor».

Martín Dobrizhoffer a Antonio Miranda.

Martín Dobrizhoffer, Historia de los abipones, t. I, pág. 33.

—No es tan bravo el león como lo pintan. 
Montevideo, 1810

«El cascabel sonaba, me añadió, y no se sabía donde estaba pero ya se ha descubierto porque se sabe que Pueyrredón se ha venido del Janeiro y se halla en Buenos Aires».

José Manuel Pérez Castellano a Miguel de Lardizábal y Uribe.

Fernando Mañé Garzón, Vida y obra de José Manuel Pérez Castellano, t. III, pág. 169.

-Oír campanas y no saber donde (Delfín Carbonell Basset, Diccionario panhispánico de refranes, Barcelona, 2002).

Córdoba, siglo XVIII

Los guaraníes al tiempo de comer guardan silencio «como si se gobernaran por el adagio español que oveja que bala pierde bocado».

Pedro Lozano, Historia de la conquista del Paraguay, Río de la Plata y Tucumán, t. I, pág. 395.

-Oveja que bala bocado pierde (D A).

Chaco, mediados del siglo XVIII

«A diario nosotros mismos vimos que ellos hacían parir a los montes y nacía un ridículo ratón».

Martín Dobrizhoffer, Historia de los abipones, t. III, pág. 157.

-Parturiunt montes: nascetur ridiculus mus (Horacio).

Chaco, mediados del siglo XVIII

«aquel axioma de los jurisconsultos partus sequitur ventrem».

Martín Dobrizhoffer, Historia de los abipones, t. I, pág. 351.

-Partus sequitur ventrem (Sbarbi $\mathrm{X}$ ).

Montevideo, 1803

«Si es de alguna verdad aquel adagio común parum pro nihilo reputatur».

Observaciones hechas al Consejo de Indias por los beneficiados de Montevideo en respuesta al informe que sobre sus novenos dio el Contador General.

Fernando Mañé Garzón, Vida y obra de José Manuel Pérez Castellano, t. III, pág. 149.

Buenos Aires, 10-V-1794

«de las piedras no se puede sacar aceite ni es buen vasallo ni consejero el que con nuevas imposiciones cree aumentar el Fisco». 
La Real Audiencia de Buenos Aires al Rey.

Archivo Histórico de la Provincia de Buenos Aires. Libro de informes y oficios de la Real Audiencia de Buenos Aires (1785-1810), Adv. de Ricardo Levene, La Plata, 1929, pág. 79.

Buenos Aires, 1800

«ha llegado el extremo de poner los ratones el cascabel al gato».

Francisco de Serra y Canals, El celo del español y el indiano instruido. Estudio preliminar de Jorge Comadrán Ruiz, Buenos Aires, 1979, pág. 43.

-Poner el cascabel al gato (JCV).

Buenos Aires, 1808

«Primero es la obligación que la devoción».

Jaime Alsina a Pascual Parodi.

Gabriela Dalla CorTe, Vida i morti d'una aventura al Riu de la Plata. Jaime Alsina y Verjés 1770-1836, Barcelona, 2000, pág. 71.

-Primero es la obligación que la devoción (RM I).

Río de la Plata, fines del siglo XVIII

Alvar Núñez deja el poder a Salazar de Espinosa «para (lo que dice Guzmán) quemar el monte con su propia leña».

Juan Francisco Aguirre, Discurso histórico sobre el Paraguay, estudio preliminar y restitución del texto por Ernesto J. A. Maeder, Buenos Aires, 2003, pág. 115.

—Del monte sale quien el monte quema (F E).

Córdoba, 176-1772

El obispo Manuel Abad Illana «acordábase mucho de aquello de pastor aborrecido, ganado perdido».

Juan Domingo Zamácola y Jáuregui, Vida de monseñor Manuel Abad Illana, estudio preliminar de José Antonio Benito Rodríguez, Arequipa, 1997, pág. 75 .

Reducción de San Javier, 1749-1767

«Las perlitas no se deben echar a los puercos».

Florián Paucke, Hacia allá y para acá, Adv. de R. A. Altieri, t. II, Tucumán, 1943, pág. 253.

-No deis a los perros las cosas santas ni echéis vuestras perlas a los cerdos (Mateo, VII 6). 
Córdoba, siglo XVIII

«Quien malas mañas ha, como dice el adagio castellano, tarde o nunca las perderá».

Pedro Lozano, Historia de las revoluciones de la provincia del Paraguay, t. I, Buenos Aires, 1905, pág. 351.

-Quien malas mañas ha, tarde o nunca las perderá (F E).

Buenos Aires, 1807-1810

«Nadie porfíe ni espere

vencer efectos del hado,

que el que ha de ser desdichado

entre los remedios muere».

José Serra y Vall, Colección de versos (Buenos Aires 1807-1810), estudio preliminar de Daisy Rípodas Ardanaz, Buenos Aires, 2000, pág. 70.

-En un texto potosino de 1800 se lee que «Quien nació desgraciado entre los remedios muere» (José M. Mariluz Urquijo, Refranero, pág. 101).

Tupiza, 3-X-1801

«Ya habrá llegado el situado y v. habrá visto lo ridículo de mi regalo, pero desde antaño tengo oído que Quien no tiene más, con su mujer se acuesta».

Vicente Anastasio Echevarría a su tía al enviarle dos objetos de plata.

Archivo Marc, Rosario.

-Quien no tiene más con su mujer se acuesta (Gonzalo Soto Posada, La sabiduría criolla. Refranero hispanoamericano, Barcelona, 1997).

Tucumán, siglo XVIII

«Quien usa de su derecho a nadie hace injuria. Séame lícito por esta regla instruir a mis apoderados».

Juan Manuel FERnÁndez Campero, «Instrucción a sus apoderados», en Manuel Lizondo Borda, Historia del Tucumán (siglos XVII y XVIII), Tucumán, 1941, pág. 146.

-Quien su derecho cumple a nadie nuce (MK).

-Qui iure suo utitur, neminem laedit.

Córdoba, 23-VIII-1768

«Qui prior est tempore, potior est jure».

El obispo Manuel Abad Illana al Rey.

P. A. Larrouy, Documentos del Archivo de Indias para la historia del Tucumán, t. II, pág. 311.

—Qui prior est tempore potior est jure (Codex 54 de RJ in $6^{\circ} 5,12$ ). 
Buenos Aires, 1715

«Quot homines, tot sententiae».

William Toller, «Historia de un viaje al Río de la Plata y Buenos Aires desde Inglaterra», en Daisy Rípodas Ardanaz (ed.), Viajeros al Río de la Plata 1701-1725, Buenos Aires, 2002, pág. 357.

—Quot homines tot sententiae (Terencio, Phormio, v. 454 (act. II, sc. 4); Cicerón, De finibus bonorum et malorum, lib. I, núm. 15).

Chaco, mediados del siglo XVIII

«En América, sobre todo, tiene lugar el antiguo adagio el rebaño será cual sea su Rey».

Martín Dobrizhoffer, Historia de los abipones, t. III, pág. 112. El P. Guillermo Furlong en Florián Paucke y sus cartas al visitador Contucci (1762-1764), Buenos Aires, 1972, pág. 37 al transcribir este mismo párrafo de Dobrizhoffer consigna la versión de «el rebaño será como sea su pastor».

—Cual el Rey, tal la grey (José Gella IturRiaga, Refranero jurídico español, Madrid, 1987).

Montevideo, 1798

«a la máxima salus publica suprema lex esto, que el bien público es la soberana ley que debe seguirse se juntará la necesidad, que carece de ley según la regla cuarta del derecho canónico».

José Manuel PÉrez Castellano, «Informe sobre el modo de conducir el agua a la ciudad».

Fernando Mañé Garzón, Vida y obra de José Manuel Pérez Castellano, t. III, pág. 36.

-Salus populi suprema lex esto (CiCERón, De legibus III, 3).

—Quod non est licitum lege, necessitas facit licitum (Decretal. Gregor. IX, lib. V, tít. XLI, cap. IV).

Montevideo, 1808

«teniendo el honor de haber sido elegido por vocal de esta junta, ni puedo dejar de cumplir con la sagrada obligación que me ha impuesto la patria y cuya salud es la suprema ley ni puedo por ahora comparecer personalmente a dar cuenta de mi conducta al tribunal de VSI».

José Manuel Pérez Castellano al obispo Benito Lué, en Fernando Mañé GARZón, Vida y obra de José Manuel Pérez Castellano, t. III, pág. 194.

—Alusión a la frase salus populi suprema lex esto. 
Buenos Aires, 1808

Para ganar un pleito hay que «tener razón y que los jueces se la quieran dar».

Jaime Alsina a Pascual Parodi, en Gabriela dalla Corte, Vida i mort d'una aventura al Riu de la Plata, pág. 125.

-Tres cosas son menester para justicia alcanzar: tener razón, saberla pedir y que la quieran dar (RM I).

Reducción de San Javier, 1749-1767

«Así ocurre en un país donde el tuerto es rey porque todos son ciegos». «Y si bien yo al igual del tuerto rey en el reino de los ciegos pasaba en este reino de la ignorancia por un maestro»...

Florián PaucKe, Hacia allá y para acá, t. II, págs. 51 y 279.

-En la tierra de los ciegos el tuerto es rey $(\mathrm{C})$.

Buenos Aires, 27-VIII-1794

«cuán cierto es que un error llama a otro».

Real Audiencia de Buenos Aires al Rey.

Archivo Histórico de la Provincia de Buenos Aires, Libro de Informes y Oficios de la Real Audiencia (1785-1810), Adv. de Ricardo Levene, La Plata, 1929, pág. 88.

-De un error muchos en pos (MK).

Plata, 25-II-1800

"Qué verdadero es el adagio un loco hace ciento».

Juan José de la Fuente a Vicente Anastasio de Echevarría.

Archivo Marc, Rosario.

-Un loco hace ciento (C).

Montevideo, 6-VII-1808

«Yo solo poco puedo hacer porque es adagio común entre los botánicos que unus homo nullus homo».

Dámaso Antonio de Larragaña a Bartolomé Doroteo Muñoz, en Guillermo Furlong, Naturalistas argentinos, Buenos Aires, 1948, pág. 375.

Montevideo, 1787

«Quedo impuesto de la satisfacción con que mi hermana Francisca escoge novios, allá se las avenga que yo no he de dormir con ellos y a la verdad te digo que ya no está la niña para andar en devaneos y que debe mirar que es ya viejo Pedro para cabrero». 
Manuel Joaquín de Toca a su primo.

Adolfo Alizaincin, Marisa Malcuori y Virginia Bertolotti, El español en la Banda Oriental del siglo XVIII, pág. 129.

—Viejo es Pedro para cabrero (D A).

Río de la Plata, hacia 1772

«Ya escampa, dijo al visitador y antes que lluevan bolazos, ya que no hay guijarros, vámonos a la tropa».

Concolorcorvo (seud. de Alonso Carrió de la Vandera), El lazarillo de ciegos y caminantes desde Buenos Aires hasta Lima, cap. VIII.

- Ya escampa y llovían chuzos de punta -o guijarros- o ladrillos (RM I).

Clave de siglas y menciones incompletas

C: Maestro Gonzalo Correas, Vocabulario de refranes y frases proverbiales y otras fórmulas comunes de la lengua castellana, Madrid, 1924.

DA: Real Academia Española, Diccionario de Autoridades. Edición facsímil, Madrid, 1963, tres volúmenes.

FE: Francisco de Espinosa, Refranero (1527-1547). Edición de Eleanor S. O'Kane, Madrid, 1968.

HN: HERnÁn NúñEz, Refranero español, Valencia, s.d.

Iribarren. José María Iribarren, El porqué de los dichos, Pamplona, 1993.

JCV: José Calles Vales y Belén Bermejo MelÉndez, Dichos y frases hechas, Buenos Aires, 2000.

JGI: Juan Gella IturRiaga, Refranero del mar, Madrid, 1944.

MK: Luis Martínez Kleiser, Refranero general ideologico español, Madrid, 1953.

RM I: Francisco Rodríguez Marín, Más de 21.000 refranes castellanos no contenidos en la colección del maestro Gonzalo Correas, Madrid, 1926.

Sbarbi: José María SваRBi, El refranero general español, Madrid, 1874-1878, diez volúmenes.

SP: Jorge Sintes Pro, Diccionario de aforismos, proverbios y refranes, Barcelona, 1961. 